\title{
Long-term care insurance research and trajectory
}

\author{
Joan Costa-Font ${ }^{1} \cdot$ Christophe Courbage $^{2} \cdot$ Joël Wagner $^{3,4}$
}

(c) The Geneva Association 2019

The financial risk of facing the costs associated with future needs for long-term care (LTC)—i.e., care for people dependent on help with their daily living activities — is still largely underinsured. In fact, the cost of LTC can even be catastrophic, resulting in ruin for a number of elderly people and their families. Financing LTC risk is therefore becoming a pressing issue for many countries confronted with an ageing population and growing LTC needs (see, e.g., Fuino and Wagner 2018b). This special issue of The Geneva Papers on Risk and Insurance is devoted to the role of insurance in financing LTC, and addresses three topics in particular: the reasons for a limited development of LTC insurance markets, the effect of LTC insurance purchase on the financial well-being of individuals, and the major research areas, both current and future, in the field of LTC insurance.

While LTC is mainly financed by governments through different types of public programmes, the limited level of public coverage, which is often means- or needstested, as well as increasing budgetary constraints have prompted a move towards developing insurance designs that address the specific institutional constraints of each country (Costa-Font et al. 2015). However, so far the market size for the different LTC insurance schemes has been relatively small in comparison to the very substantial amount of private expenditure and the significant level of self-insurance by families (Costa-Font 2010). The slow insurance development can be accounted for by a number of supply and demand factors, some of which this special issue discusses and advances in its study. Such supply factors include questions associated with risk insurability, asymmetric information and pricing (Fuino and Wagner 2018a). As for demand factors, potential cognitive biases in risk perception, awareness of caregiving needs and the burden on family (Sloan and Norton 1997), and

Christophe Courbage

christophe.courbage@ hesge.ch

1 London School of Economics, London, England, UK

2 Geneva School of Business Administration (HES-SO), Geneva, Switzerland

3 Department of Actuarial Science, Faculty of Business and Economics, University of Lausanne, Lausanne, Switzerland

4 Swiss Finance Institute, University of Lausanne, Lausanne, Switzerland 
more especially the crowding out of public assistance (Brown and Finkelstein 2008) and of family support (Pauly 1990) are relevant drivers.

The first set of papers published in this special issue investigate further those demand-side factors that could explain why the LTC insurance market is limited in size, focusing on LTC risk perception and family altruism.

The paper by Martin Boyer, Philippe De Donder, Claude Fluet, Marie-Louise Leroux and Pierre-Carl Michaud reports survey evidence on LTC risk misperceptions and demand for LTC insurance in Canada. To assess LTC risk misperceptions, they contrast subjective (stated) probabilities with objective (predicted) probabilities of needing help in the form of home care, access to a nursing home and living to the age of 85 . They find that survey respondents' misperceptions are quite small on average when assessing their LTC risk. Respondents are on average optimistic about their need for home care and about their survival probability but pessimistic about their nursing home need. They also find that, although misperceptions significantly affect both the intention to buy LTC insurance and the actual purchase of LTC insurance, they cannot explain the low take-up rate of LTC insurance in their sample. Correcting misperceptions would slightly increase LTC insurance take-up. Such results suggest that the awareness of risk misperceptions is only one explanation among many others for the small market for LTC insurance.

The paper by Justina Klimaviciute, Pierre Pestieau and Jérôme Schoenmaeckers analyses LTC insurance purchase decisions when parents expect to receive assistance from altruistic children. After proposing a simple theoretical model from which they construct various hypotheses on the parents' insurance decision, they run an empirical test using data from the U.S., France, Spain, Germany and Israel. They find that the effect of children's altruism is negative in Germany and Israel but not significant in the U.S., France and Spain, which possibly suggests that the different forces identified in the theoretical model-i.e., the degree of substitutability between informal and formal care, the degree of parental altruism and the intensity of risk aversion-offset each other. While family altruism is often cited among the factors explaining the thinness of the LTC insurance market, their paper indicates that in some countries, particularly in the U.S. and in France, family altruism does not play such an important role.

The second set of papers address the limitations of LTC insurance markets from a supply-side perspective and, more especially, investigate the role of moral hazard and solvency regulation in explaining the high level of LTC insurance premiums potentially deterring purchase.

In private LTC insurance markets, moral hazard is central to pricing and the longrun robustness of the market. Yet there is remarkably little evidence on the extent to which moral hazard exists in the presence of LTC insurance. The paper by Tamara Konetzka, Daifeng He, Jing Dong and John Nyman uses Health and Retirement Study data from 1996 to 2014 to assess moral hazard in nursing home and home care use in private LTC insurance. The research employs a combination of propensity score matching and instrumental variables approaches. They find evidence of significant moral hazard in home care use and a potentially meaningful but noisy effect on nursing home use. Their results suggest that policymakers, in designing incentives to promote private LTC insurance ownership, should consider the additional 
spending associated with moral hazard and potentially incorporate disincentives for socially inefficient spending by policyholders.

The paper by Franca Glenzer and Bertrand Achou aims at quantifying markups of premiums for LTC insurance due to mortality and morbidity risk. To this end, they model a shareholder value maximising insurance company that is subject to solvency regulation. Because liabilities from LTC insurance (which depend on future morbidity and mortality) are more volatile than liabilities from annuities (which only depend on future mortality), capital provisions to ensure compliance with regulatory solvency requirements are higher if an insurance company offers LTC insurance instead of annuities. At the same time, a higher volatility in the LTC insurance segment also implies a higher expected payoff to the insurance company's shareholders. Their results show that offering LTC insurance increases the upside potential to shareholders, but that effect is more than offset by a higher need for external capital. Consequently, if shareholders are to accept an LTC insurance segment, policyholders of an LTC insurance policy need to pay considerable markups, which increases the importance of LTC insurance in the insurer's overall book of business, explaining the high level of premium for LTC insurance.

Since financial protection is arguably the primary purpose of any insurance, LTC insurance can play an important role in financial planning for the elderly. However, there is little empirical evidence on the economic consequences of having LTC insurance, apart from its effects mainly on health services utilisation and informal caregiver outcomes. The paper by Jing Dong, Fabrice Smieliauskas and Tamara Konetzka tries to fill that gap by examining how LTC insurance affects key financial outcomes of insured individuals using U.S. Health and Retirement Study data. They find that LTC insurance leads to consistently positive effects on assets, consistently negative effects on Medicaid and Food Stamp enrolment, as well as parent-child financial transfers and ambiguous effects on out-of-pocket medical payments. These results suggest that although private LTC insurance does not entirely protect insured individuals against large medical expenditures, it improves the general financial well-being of insured individuals, potentially by reducing Medicaid-related disincentives to asset accumulation, motivating individuals to save more and reduce intergenerational wealth transfers.

Last but not least, the final paper of this special issue by Martin Eling and Omid Ghavibazoo provides a structured literature review of LTC insurance using main path analysis. They identify three major research areas (financing, demand, and insurability) and systematically evaluate them based on standard frameworks. Their results illustrate the significant difficulties of insuring LTC both on the demand and supply sides, explaining the low contribution of insurance mechanisms to LTC financing. They also highlight the potential contribution of combined products that bundle the risks and public-private partnerships that integrate LTC into the pension systems, thus helping to overcome the insurability limitations. Alternative financing methods that go beyond the idea of risk pooling (LTC bonds, LTC put options, equity releases) are also discussed as a way to improve the sustainability of LTC financing.

The papers in this collection inevitably refer to just a few of the many issues linked to the role of insurance in covering LTC risk. We are convinced that these 
papers provide important messages for policymakers and other stakeholders on how to efficiently organise and manage the financing of LTC risk. Finally, we express our deep gratitude to all the authors who contributed to this issue. We have been privileged to benefit from the insights of their research, and we hope that you will appreciate reading their contributions to this special issue of The Geneva Papers on Risk and Insurance.

Acknowledgements Christophe Courbage and Joël Wagner acknowledge financial support from the Swiss National Science Foundation (Grant N ${ }^{\circ}$ 100018_169662) and thank Guillem Montoliu and Michel Fuino for their help in preparing this special issue.

\section{References}

Brown, J.R., and A. Finkelstein. 2008. The interaction of public and private insurance: Medicaid and the long-term care insurance market. American Economic Review 98 (3): 1083-1102.

Costa-Font, J., C. Courbage, and K. Swartz. 2015. Financing long-term care: Ex ante, ex post or both? Health Economics 24 (S1): 45-57.

Costa-Font, J. 2010. Family ties and the crowding out of long-term care insurance. Oxford Review of Economic Policy 26 (4): 691-712.

Fuino, M., and J. Wagner. 2018a. Long-term care models and dependence probability tables by acuity level: New empirical evidence from Switzerland. Insurance: Mathematics and Economics 81: 51-70.

Fuino, M., and J. Wagner. 2018b. Old-age care prevalence in Switzerland: Drivers and future development. European Actuarial Journal 8 (2): 321-362.

Pauly, M.V. 1990. The rational nonpurchase of long-term-care insurance. Journal of Political Economy 98 (1): 153-168.

Sloan, F.A., and E.C. Norton. 1997. Adverse selection, bequests, crowding out, and private demand for insurance: Evidence from the long-term care insurance market. Journal of Risk and Uncertainty 15 (3): 201-219.

Publisher's Note Springer Nature remains neutral with regard to jurisdictional claims in published maps and institutional affiliations. 